\title{
Development Trends of Online-based Aural Rehabilitation Programs for Children with Cochlear Implant Coping with the Fourth Industrial Revolution and Implication in Speech-Language Pathology
}

\author{
Haewon Byeon \\ Department of Speech Language Pathology \\ Honam University, Gwangju, Republic of Korea
}

\begin{abstract}
The Korea Research Foundation selected the miniaturization and development of home care devices as the future promising technologies in the biotechnology (BT) area along with the Fourth Industrial Revolution. Accordingly, it is believed that there will be innovative changes in the rehabilitation field, including the development of smart diagnostics and treatment devices. Moreover, rehabilitation equipped with individualization, precision, miniaturization, portability, and accessibility is expected to draw attention. It has been continuously reported in the past decade that hearingimpaired toddlers who became able to hear speech through cochlear implantation and hearing rehabilitation before the age of 3 , which is a critical period of language development, show a language development pattern similar to that of healthy toddlers. As a result, the need for developing language rehabilitation programs customized for patients wearing artificial cochlea has emerged. In other words, since the improved hearing ability owing to cochlear implant does not guarantee to promote speech perception and language development, intensive rehabilitation and education are needed for patients to recognize the heard speech as a meaningful language for communication. Nevertheless, a literature search on domestic and foreign cases revealed that there are insufficient language rehabilitation programs for cochlear implant patients as well as customized programs for them in the clinical coalface. This study examined the trend and marketability of online-based aural rehabilitation programs for patients wearing artificial cochlea and described the implications for language rehabilitation. This study suggested the following implications for developing a customized aural rehabilitation program. It is needed to secure and develop contents that can implement "a hand-held hospital" by using medical devices and mobile devices owned by consumers that transcend time and space. Also, it is necessary to develop a cochlear implant hearing rehabilitation training program suitable for native Korean speakers.
\end{abstract}

Keywords-Cochlear implant; future promising technologies; smart diagnostics; Online-based aural rehabilitation

\section{INTRODUCTION}

The number of people suffering from hearing loss is continuously increasing in South Korea. The Health Insurance Review \& Assessment Service (2018) reported that the number of patients who visited medical clinics due to hearing loss increased by $18.7 \%$ in five years, from 746,499 in 2012 to 886,091 in 2016. It is believed that the number of patients with potential hearing loss is higher than recorded because many people with hearing problems do not visit medical clinics. According to the Korea Centers for Disease Control and Prevention (2016), one of two patients with hearing loss did not visit a medical clinic until they had a major obstacle in their daily life and only 12.6 percent of them used assisting devices such as a hearing aid, even though they were diagnosed with hearing loss. It is projected the number of patients with hearing loss will increase steadily because the noise environment is getting more severe due to continuing industrialization.

The artificial cochlea is a device that delivers sound to the inner ear's auditory nerve through artificial electrical stimulation [1]. The cochlear implant has been mainly applied to children with the highest degree hearing impairment who gain little by wearing hearing aids. Since cochlear implantation was approved by the Food and Drug Administration (FDA) in 1990, the number of cochlear implant patients has increased drastically worldwide. The cochlear implant surgery has been covered by health insurance since 2005 in South Korea, and patients just need to bear $20 \%$ of the cost from examination to surgery. Therefore, it is expected that the market size will be expanded rapidly. Additionally, it is projected that the future of artificial cochlea related rehabilitation business is bright because the medical expense of South Korean patients with hearing loss has increased by $12.6 \%$ in the past five years and the number of patients with hearing loss in their $20 \mathrm{~s}$ is increasing every year.

In particular, the number of patients with presbyacusia is increasing in South Korea due to aging. It is hard to diagnose and treat presbyacusia because the elderly do not recognize that their hearing has been deteriorated over a considerable period of time and their cochleae have been damaged gradually. Lin et al. (2011) [2] reported that people with presbyacusia were more likely to suffer from Alzheimer's dementia because the sound stimulation to the brain would be decreased since they could not hear spoken words clearly for a long time and it ultimately deteriorated cognitive ability and memory power. 
Consequently, it is expected that the cochlear implant surgery will be expanded to the elderly population due to the increased population with presbyacusia [3]. Furthermore, the Korea Research Foundation (2017) [4] elected the miniaturization and development of home care devices as the future promising technologies in the biotechnology (BT) area along with the Fourth Industrial Revolution. Accordingly, it is believed that there will be innovative changes in the rehabilitation field, including the development of smart diagnostics and treatment devices. Moreover, rehabilitation equipped with individualization, precision, miniaturization, portability, and accessibility is expected to draw attention.

It has been continuously reported in the past decade that hearing-impaired toddlers who became able to hear speech through cochlear implantation and hearing rehabilitation before the age of 3 , which is a critical period of language development, show a language development pattern similar to that of healthy toddlers $[5,6,7,8,9,10,11,12]$. As a result, the need for developing language rehabilitation programs customized for patients wearing artificial cochlea has emerged [13]. In other words, since the improved hearing ability owing to cochlear implant does not guarantee to promote speech perception and language development, intensive rehabilitation and education are needed for patients to recognize the heard speech as a meaningful language for communication [14]. Nevertheless, a literature search on domestic and foreign cases revealed that there are insufficient language rehabilitation programs for cochlear implant patients as well as customized programs for them in the clinical coalface. This study examined the trend and marketability of online-based aural rehabilitation programs for patients wearing artificial cochlea and described the implications for language rehabilitation.

\section{COCHLEAR IMPLANT AND COMMUNICATION SKILLS}

Accurately listening and generating speech are essential skills in communication but, in the case of sensorineural hearing loss, which occurs when a part or all of the auditory nerve is damaged, it is difficult to restore general communication abilities only by prescribing a hearing aid. Particularly, since these patients hear many consonants in the high-frequency range distortedly in a spoken language condition (Fig. 1), they are generally recommended to have a cochlear implant (Fig. 2).

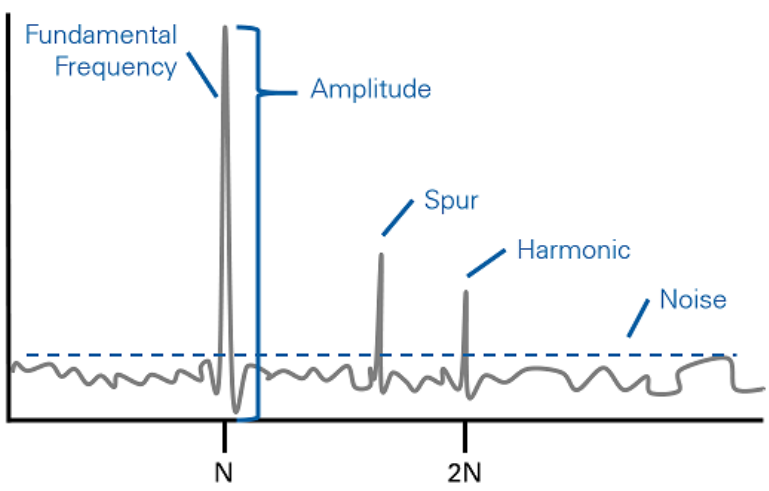

Fig. 1. Fourier Transform for Frequency Domain Visualization.

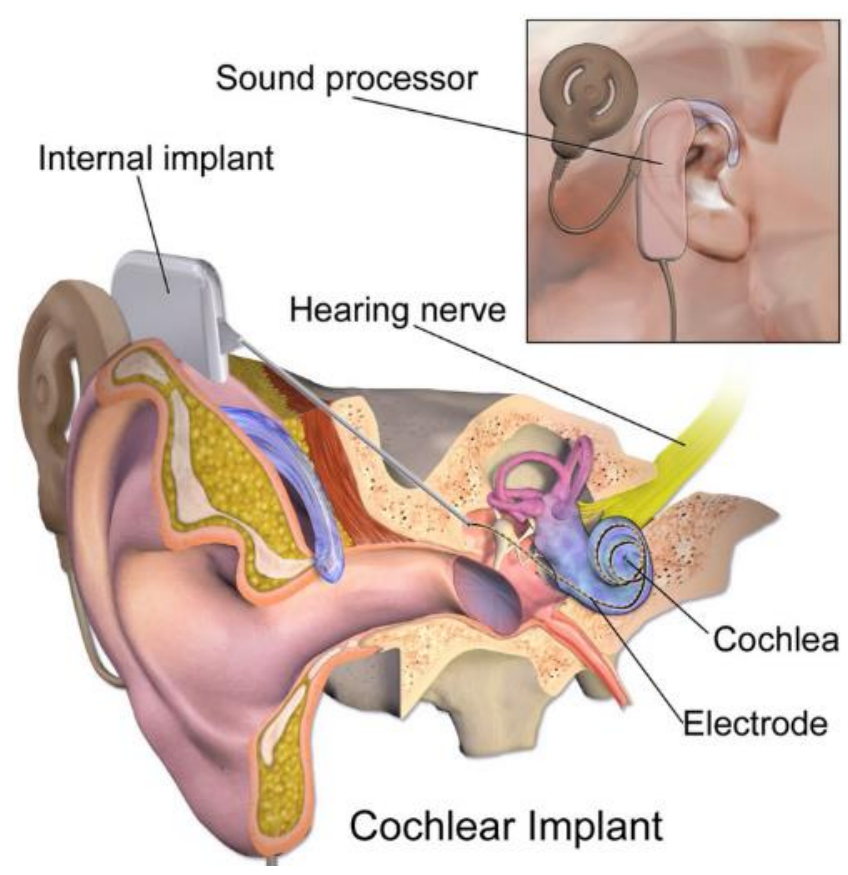

Fig. 2. Structure and Concept of Cochlear Implant, Source: American Speech-Language-Hearing Association (2004).

Cochlear implantation is an electrode insertion surgery that implants the electrode, which converts an incoming sound into a voice signal to stimulate the auditory nerve and transmits the delivered electrical stimulation to the brain, into the cochlea. The artificial cochlea directly stimulates the spiral ganglion cells or peripheral auditory nerves that remain in the cochlea to help the auditory center recognize the sound. It is possible to confirm that the audible threshold for each frequency increases after having a cochlear implant (Fig. 3). Especially, it was found that the threshold in the low-frequency range (left (red) of Fig. 3) and that in the high-frequency range (right (blue) of Fig. 3) increased.

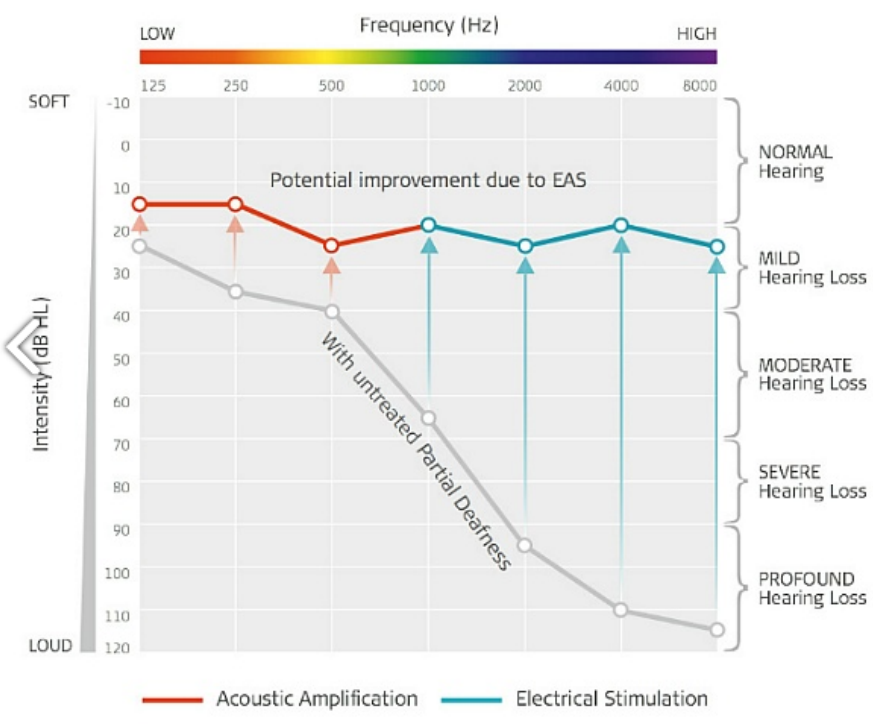

Fig. 3. Efficacy of Hearing Elevation after Cochlear Implantation. 


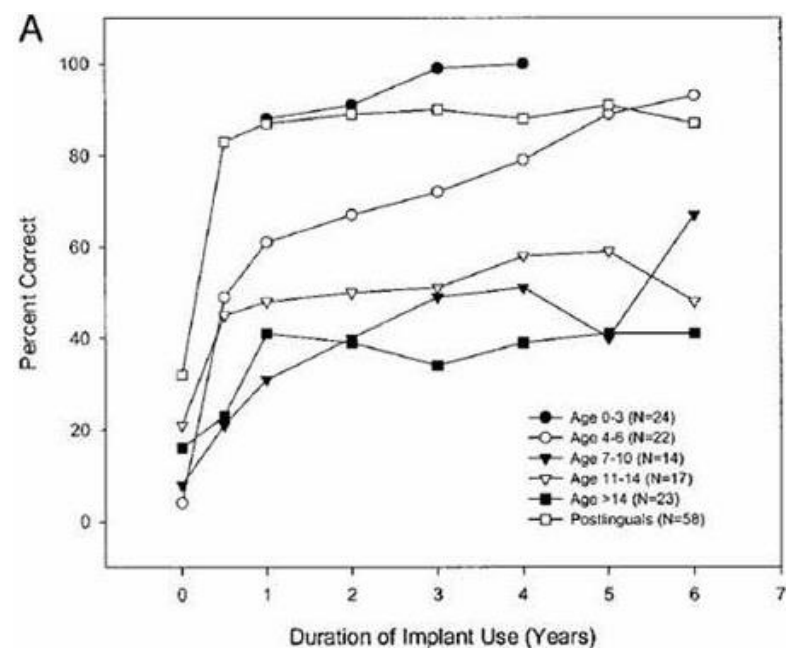

Fig. 4. Effect of Cochlear Implantation According to Rehabilitation Period, Source: Dunn, et al. (2008) [16].

Cochlear implantation for children with hearing impairment shows revolutionary results in the aspect that it improves the hearing ability of children. The improvement of speaking and language ability after cochlear implantation varies by various factors such as the age of hearing loss initiation, cause of hearing loss, duration of hearing loss, the residual hearing before an operation, and communication methods. American Speech-Language-Hearing Association (2004) [15] reported that hearing ability improved when the duration of hearing rehabilitation and artificial cochlea usage is lengthened. Dunn et al. (2008) [16] showed that, although it varied by the age of a patient, when patients underwent hearing rehabilitation steadily after cochlear implantation, they could distinguish common sounds, such as ambient sounds approximately one year after the surgery, $70-80 \%$ of children could understand everyday words approximately 2 years after the surgery, and $70 \%$ of children could have a conversation without using lip reading after 4 years (Fig. 4 ).

\section{THE NeCESSITY OF CUSTOMIZED AurAL REHABILITATION PROGRAMS FOR CHILDREN WITH COCHLEAR IMPLANTS}

Patients cannot recognize all sounds immediately after cochlear implantation. Unlike the general public who hears the amplified sound, the cochlear implant patients hear by converting sounds into electrical signals. Therefore, they need additional adaptive training after surgery. Tye-Murray (2016) [17] reported that the degree of communication improvement depended on by children's learning style, skills of professionals, task presentation method, and task performance ability. In particular, unlike ambient noise, speech is composed of sounds using various frequency ranges and capricious sounds. Therefore, customized aural rehabilitation is essential. According to Tye-Murray (2019) [14], speech perception is made in the phoneme unit that causes semantic differences (e.g., row vs. low) and is related to the sense development of children.

Therefore, the speech perception program of cochlear implant subjects should consider the semantic development characteristics of the subjects as well as the phoneme characteristics of Korean consonants. Hearing-impaired people have a relatively hard time recognizing words based on consonants compared to those based on vowels in speech perception. Therefore, consonant discrimination and identification are factors that take a long time in hearing rehabilitation of cochlear implant subjects. It is necessary to develop customized aural rehabilitation programs considering the characteristics of Korean phonemes (universal characteristics) and those of semantic development (individual characteristics).

\section{CONVERGENCE OF INFORMATION AND COMMUNICATION TECHNOLOGY (ICT) AND HEALTHCARE}

The Fourth Industrial Revolution, which combines ICT and rehabilitation science, is expected to break down the boundaries between industries, brings about various forms of convergence and competition, and causes new changes. Among them, it is believed that the healthcare industry has a huge growth potential owing to the convergence of new ICT technologies because the efficiency of the industry is very low, although it is already quite large.

The market size of the global digital healthcare industry continues to grow due to the aging of the world's population and the increase in patients with chronic diseases (Fig. 5). The market size has already reached $\$ 96$ billion in 2016 and will be $\$ 206$ billion by 2020 by growing by $21.1 \%$ annually. More specifically, mobile health will become the main trend in digital healthcare for a while.

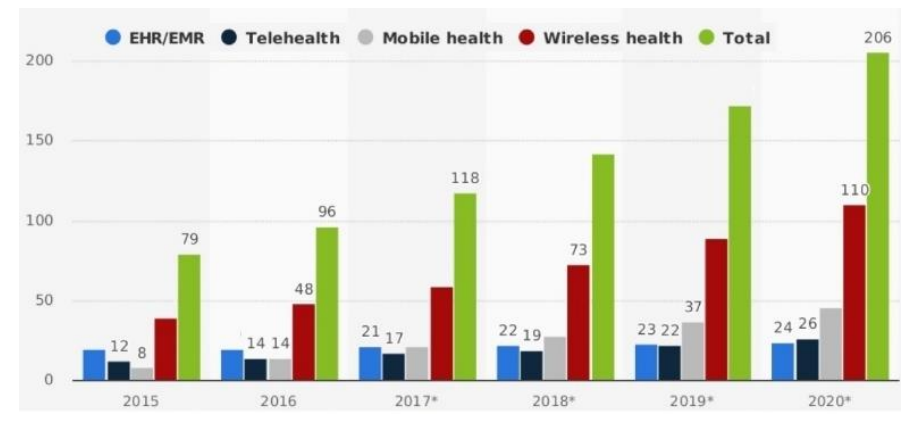

Fig. 5. Prospect of the Global Digital Healthcare Industry.

\section{THE NEED For A CUSTOMIZED SMART AUditory REHABILITATION SYSTEM}

Most cochlear implant patients receive aural rehabilitation at the ENT Hearing Loss Center of a University Hospital or a Speech Therapy Center specialized for hearing rehabilitation. However, aural rehabilitation has spatial and temporal limitations and costs a lot of time and money because it is performed by 1:1 individualized therapy. Moreover, it is difficult to obtain a rehabilitation opportunity because there are only a few hearing rehabilitation centers. Aural rehabilitation training requires the rehabilitation treatment of professional and trained therapists, but subjects are treated in general centers or hospitals without considering their characteristics because there are not enough local aural rehabilitation centers. In other words, it is necessary to develop a smart aural rehabilitation system that is not limited to spatially and temporally, based on expertise, and customized for the level of subjects. 


\section{NECESSITY OF DEVELOPING AN INDUSTRY-ACADEMIC- INSTITUTE COLLABORATION MODEL}

Various studies on wellness personalized management technologies have been actively conducted in leading countries such as the United States and Japan. In the United States, the National Sanitation Foundation has invested $\$ 330$ million in 756 projects from 2013 to 2015 (three years) to develop personalized healthcare-related technologies [18]. Europe has also invested $€ 580$ million in 247 projects on wellness personalized healthcare-related technologies from 2013 to 2015. It is required for South Korea to analyze major factors in the cochlear implant-related market and actively develop industry-academic-institute collaboration models. Especially, it is needed to secure and develop contents that can implement "a hand-held hospital" by using medical devices and mobile devices owned by consumers.

\section{GROWTH OF THE MOBILE HeAlthCARE MARKET}

Mobile healthcare refers to a system where patients and doctors can give or receive medical services without being constrained by time and space. It is defined as checking and managing own health status by using a smartphone and medical applications. The market size of the global mobile healthcare industry is approximately $\$ 2.4$ billion and is believed to grow to $\$ 8$ billion by 2018. Lee (2017) [19] showed that interest in mobile healthcare is greatly increasing worldwide including South Korea (Fig. 6).

The healthcare paradigm is shifting from institutionoriented service to consumer-oriented service. Technavio (2014)[20] argued that the market size of cochlear implant is $\$ 1,590$ million as of 2014 and will grow $13.6 \%$ annually and become $\$ 2.8$ billion in 2020. Lee (2017) [21] reported that the market size of cochlear implant in South Korea is $\$ 34.6$ billion in 2014 and is increasing. Lee (2017) [21] also projected that the market size will be approximately $\$ 68.5$ by 2018 owing to an $18.6 \%$ annual grow (Fig. 7). It is believed that the growth rate of the South Korean market $(18.6 \%)$ is higher than that of the global market $(13.6 \%)$ because of the application of medical insurance, the increase of the elderly and population with hearing loss, and the improvement of income level.

The cochlear implantation was first conducted in 1989 in South Korea and it is now being performed in a number of hospitals. The operation targets and medical institutions conducting it are gradually expanding. The cost of cochlear implantation is more than $\$ 20$ million in South Korea. However, it has been covered by medical insurance since 2005, and a patient needs to pay million from examination to surgery. Therefore, it is expected that the market size will grow further.

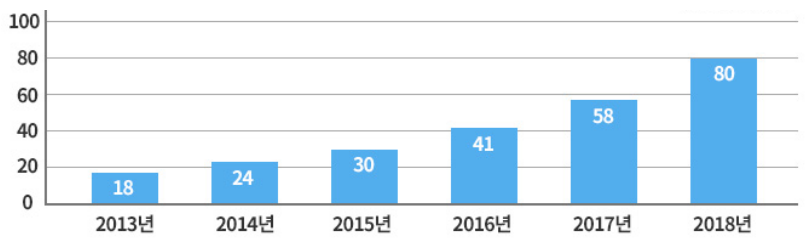

Fig. 6. The Size of the Global Mobile Healthcare Market, Source: Lee (2017) [19].

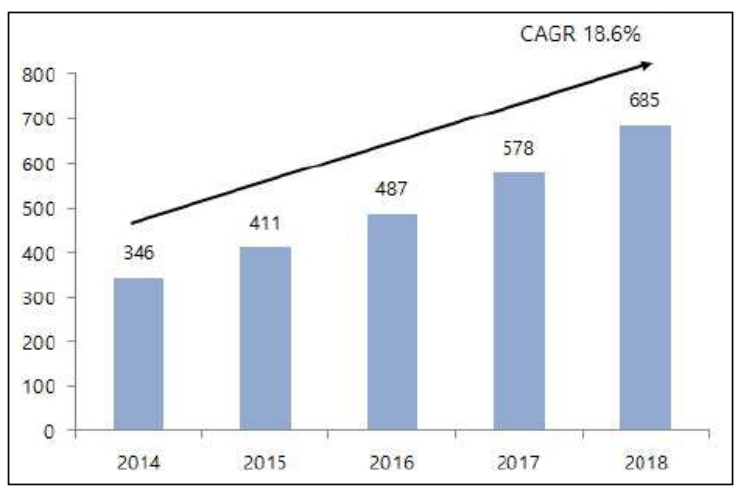

Fig. 7. Market Size of Cochlear Implant in Korea.

The Korea Centers for Disease Control and Prevention (2016) [22] reported that the number of patients with hearing loss increased from 266,348 people in 2010 to 280,460 people in $2014,5.3 \%$ annual growth. In terms of age group, people in 70 's accounted for 54,066 people (19.2\%), the largest group, followed by people in 60's (50369 people; $18 \%$ ) and people in 50 's (47,485 people; 16.9\%). Among all hearing-impaired people, $61.8 \%$ were using hearing aids and $3.4 \%$ of them underwent cochlear implantation that transform sound stimuli into auditory stimuli and deliver it to the brain. Recently, the range of patients requiring cochlear implants is gradually increasing: even patients with losing the hearing of only one ear have a cochlear implant.

\section{DEVELOPMENT STATUS AND TREND OF ONLINE AURAL REHABILITATION PROGRAMS}

Auditory Training-Spice for Life (Fig. 8) and Angel Sound (Fig. 9) have been developed and marketed in the US for ICTbased aural training [23, 24]. However, they focus on enhancing the aural memory mainly using ambient sounds, not speech and do not support Korean, which are limitations [23, 24]. Therefore, it is necessary to develop a cochlear implant hearing rehabilitation training program suitable for native Korean speakers.

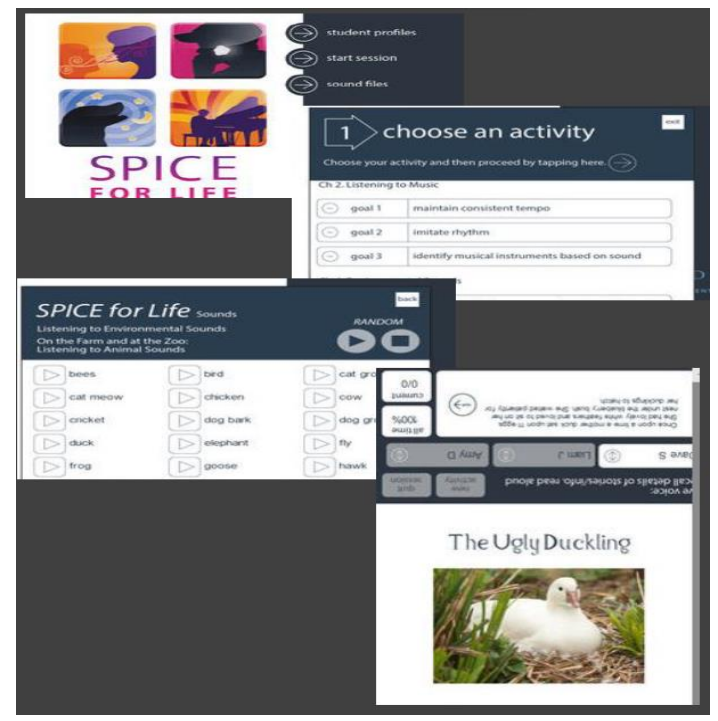

Fig. 8. Auditory Training-Spice for Life. 


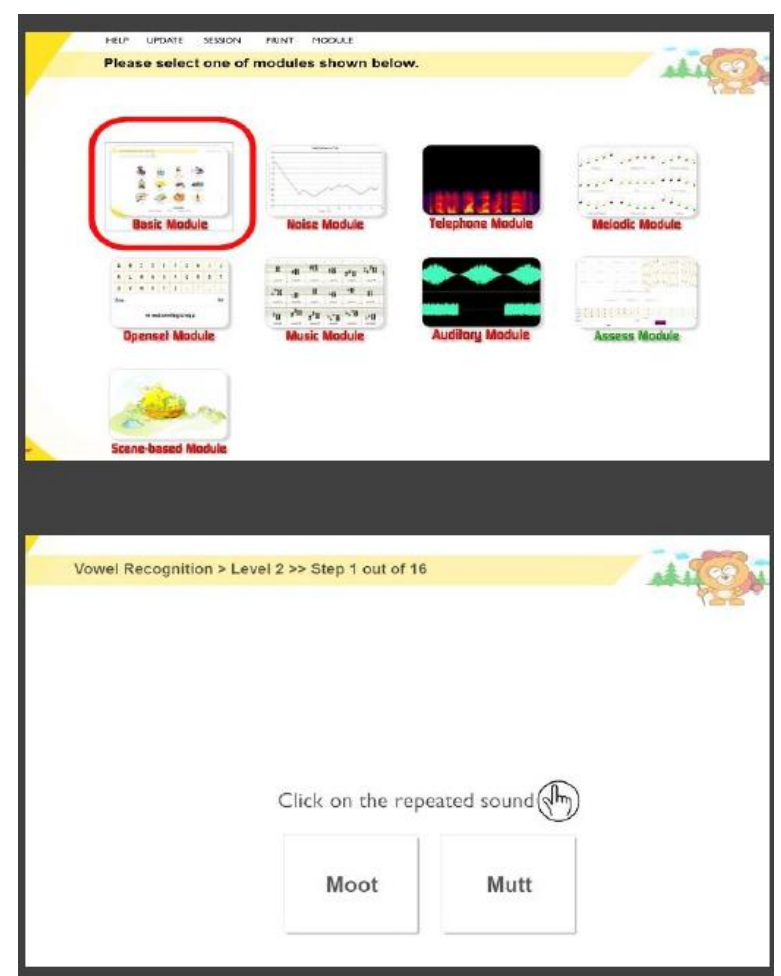

Fig. 9. Angel Sound.

Although it is needed to develop a robust ICT-based aural rehabilitation program for children and adults who need aural rehabilitation without being constrained by time and space after cochlear implantation in South Korea, programs developed by South Korean companies yet just focus on articulation training and augmentative and alternative communication. Ling 6 Sound Test App released in 2013 is the only program developed in South Korea for patients with cochlear implant. Table I shows the status of studies or intellectual property rights associated with the aural rehabilitation programs for people with cochlear implant in South Korea.

Although it is needed to develop a robust ICT-based aural rehabilitation program for children and adults who need aural rehabilitation without being constrained by time and space after cochlear implantation in South Korea, programs developed by South Korean companies yet just focus on articulation training and augmentative and alternative communication. Ling 6 Sound Test App released in 2013 is the only program developed in South Korea for patients with cochlear implant. Table I shows the status of studies or intellectual property rights associated with the aural rehabilitation programs for people with cochlear implant in South Korea.

App Annie's report (2016) [25] examined the expenditure of digital content compared to the population of seven countries (South Korea, Japan, the US, the United Kingdom, Germany, France, and Russia). The report revealed that the digital contents market of South Korea, Japan, the US, and the United Kingdom exceeded the mean of the seven countries, indicating that the South Korean market was a main market for digital content (Fig. 10).

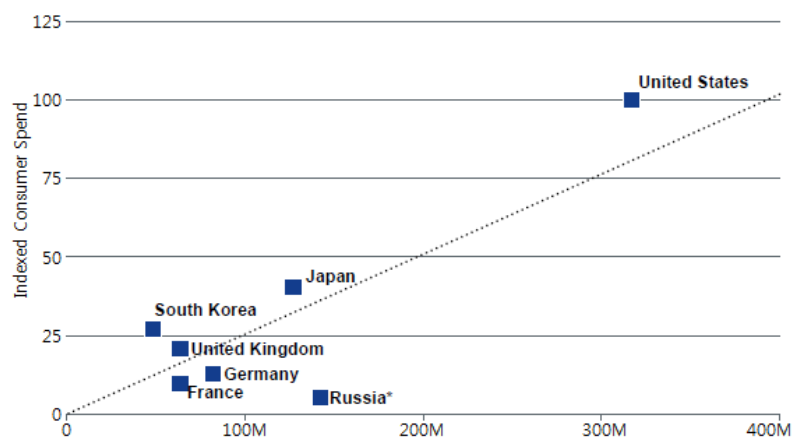

Fig. 10. Digital Content Spending Costs by Country 2016.

\section{TRENDS IN THE Digital CONTENT MARKET}

Particularly, South Korea showed the largest consumption and highest growth rate in digital content usage per device and confirmed that the South Korean market has the strongest consumption power in the world [25]. In addition, the South Korean market leads the profit of mobile apps in the smart contents market. In terms of the market size, the South Korean market was the third largest in the world after the US and Japan [25]. App Annie (2016) [25] reported that the South Korean mobile app market grew 2.3 times compared to the previous year. Although it is not yet known for the rehabilitation contents market due to lacking statistical data, it is expected that the size of the market will grow rapidly, considering the overall trend of the market.

TABLE. I. LIST OF RESEARCH OR INTELLECTUAL PROPERTY

\begin{tabular}{|c|c|c|c|}
\hline Type & Title & Institution & $\begin{array}{l}\text { Registration } \\
\text { date }\end{array}$ \\
\hline \multirow{4}{*}{$\begin{array}{l}\text { Paper \& } \\
\text { Report }\end{array}$} & $\begin{array}{l}\text { Case study of speech perception } \\
\text { enhancement in hearing-impaired } \\
\text { adult by auditory training } \\
\text { program of mobile device }\end{array}$ & $\begin{array}{l}\text { Korean } \\
\text { Academy of } \\
\text { Audiology }\end{array}$ & 2014 \\
\hline & $\begin{array}{l}\text { Development of a speech } \\
\text { recognition threshold application } \\
\text { using voice recognition } \\
\text { technology: pilot study }\end{array}$ & $\begin{array}{l}\text { Journal of } \\
\text { Speech- } \\
\text { Language \& } \\
\text { Hearing } \\
\text { Disorders }\end{array}$ & 2015 \\
\hline & $\begin{array}{l}\text { A study on mobile application } \\
\text { ux/ui design of communication } \\
\text { for the hearing \& language } \\
\text { impaired }\end{array}$ & $\begin{array}{l}\text { Journal of } \\
\text { the Korean } \\
\text { Society of } \\
\text { Design } \\
\text { Culture }\end{array}$ & 2015.06 \\
\hline & $\begin{array}{l}\text { Developing a mobile application } \\
\text { to learn korean for children with } \\
\text { hearing impairment - human- } \\
\text { centered design approach }\end{array}$ & $\begin{array}{l}\text { AAC } \\
\text { Research \& } \\
\text { Practice }\end{array}$ & 2016.06 \\
\hline \multirow{4}{*}{$\begin{array}{l}\text { Intellectual } \\
\text { property }\end{array}$} & $\begin{array}{l}\text { Smart glass system for hearing- } \\
\text { impaired communication } \\
\text { (No. 1018309080000) }\end{array}$ & $\begin{array}{l}\text { Hyunjoo } \\
\text { Park }\end{array}$ & 2018.02 .13 \\
\hline & $\begin{array}{l}\text { Auditory sense training apparatus } \\
\text { (No. 1018178340000) }\end{array}$ & Yunsik Choi & 2018.01 .05 \\
\hline & $\begin{array}{l}\text { System for aidding } \\
\text { communication of deaf person } \\
\text { (No. 1016057960000) }\end{array}$ & $\begin{array}{l}\text { Korea } \\
\text { University } \\
\text { of Social } \\
\text { Welfare }\end{array}$ & 2016.03 .17 \\
\hline & $\begin{array}{l}\text { Infants" vocal development } \\
\text { evaluation device, and system } \\
\text { and method of auditory } \\
\text { rehabilitation for infants } \\
\text { (No. 1020150102447) }\end{array}$ & $\begin{array}{l}\text { Hallym } \\
\text { University }\end{array}$ & 2015.07 .20 \\
\hline
\end{tabular}


In Korea, most ICT-based rehabilitation programs remain in articulation training or augmentative and alternative communication. The only Korean program developed for cochlear implants is the Ling 6 Sound Test App. Table I shows the status of research or intellectual property rights (patent registration) of the cochlear implant rehabilitation program developed in Korea.

\section{CONCLUSIONS}

It is necessary to develop ICT-based rehabilitation program to improve the ability of children with cochlear implant to listen to the speech sound. Since speech perception is greatly affected by the phoneme characteristics of a specific language, it is impossible to apply the results of foreign studies or use a program developed in a foreign country. Consequently, a speech perception program considering the phoneme characteristics of Korean should be developed. It is also required to develop an aural rehabilitation program that takes into account the universal language development characteristics (e.g. consonant/vowel-phonemes correspondence rules) and the normal aspects of an individual language (e.g., sense development). This study suggested the following implications for developing a customized aural rehabilitation program.

First, it is necessary to develop an aural rehabilitation training program based on smart devices. In order to promote the language development of children with cochlear implant, we must have a rehabilitation training program that can introduce verbal stimuli using sound and a systematic program for them to continuous listen and comprehend sound. It will be necessary to develop and commercialize an ICT-based program that can be applied at rehabilitation practically to provide listening training for children with cochlear implant.

Second, it is needed to develop ICT-based rehabilitation programs in order to establish the foundation for introducing new health rehabilitation technologies for the Fourth Industrial Revolution and accumulating future technologies (e.g., IoT). We shall apply for the rights and patents associated with online aural rehabilitation training programs for people with cochlear implant. Moreover, an industry-academia consortium must protect the right of new technologies by jointly applying for intellectual property rights and commercialize their technologies.

Third, it is needed to develop aural training programs customized for each hearing level. For example, we may develop an ICT-based aural rehabilitation training program by reorganizing intervention contents according to the characteristics of the Korean and the language level of a target age based on the auditory skills level determined by the Auditory Skills Program [26]. I hope that various customized aural rehabilitation programs will be developed for the hearing impaired by applying rapidly advancing ICT technologies.

\section{ACKNOWLEDGMENT}

This work was supported by the Ministry of Education of the Republic of Korea and the National Research Foundation of Korea (NRF- 2018R1D1A1B07041091 and NRF2019S1A5A8034211).

\section{REFERENCES}

[1] G. Feng, E. M. Ingvalson, T. M. Grieco-Calub, M. Y. Roberts, M. E. Ryan, P., Birmingham, D. Burrowes, N, M. Young, and P. C. Wong, Neural preservation underlies speech improvement from auditory deprivation in young cochlear implant recipients. Proceedings of the National Academy of Sciences, vol. 115, no. 5, pp. E1022-E1031, 2018.

[2] F. R. Lin, L. Ferrucci, E. J. Metter, Y. An, A. B. Zonderman, and S. M. Resnick, Hearing loss and cognition in the Baltimore longitudinal study of aging. Neuropsychology, vol. 25, no. 6, pp. 763-770, 2011.

[3] H. Olze, S. Gräbel, U. Förster, N. Zirke, L. E. Huhnd, H. Haupt, and B. Mazurek, Elderly patients benefit from cochlear implantation regarding auditory rehabilitation, quality of life, tinnitus, and stress. The Laryngoscope, vol. 122, no. 1, pp. 196-203, 2012.

[4] Korea Research Foundation. 12 future technical reports. Korea Research Foundation, Daejeon, 2017.

[5] D. J. Ertmer, Speech intelligibility in young cochlear implant recipients: gains during year three. Volta Review, vol. 107, no. 2, pp. 85-99, 2007.

[6] A. E. Geers, J. G. Nicholas, A. L. Sedey, Language skills of children with early cochlear implantation. Ear and hearing, vol. 24, no 1 , 46S58S, 2003.

[7] J. G. Nicholas, and A. E. Geers, Will they catch up? the role of age at cochlear implantation in the spoken language development of children with severe to profound hearing loss. Journal of Speech, Language, and Hearing Research, vol. 50, no. 4, pp. 1048-1062, 2007.

[8] J. N. Li, S. Chen, L. Zhai, D. Y. Han, A. A. Eshraghi, Y. Feng, S. M. Yang and X. Z. Liu, The Advances in Hearing Rehabilitation and Cochlear Implants in China. Ear and hearing, vo. 38, no. 6, pp. 647-652, 2017.

[9] G. W. Hwang, and H. J. So, Developing a mobile application to learn Korean for children with hearing impairment: human-centered design approach. AAC Research \& Practice, vol. 4, no. 1, pp. 101-123, 2016.

[10] A. Laplante-Lévesque, M. Kathleen Pichora-Fuller, and J. P. Gagné, Providing an internet-based audiological counselling programme to new hearing aid users: a qualitative study: Provisión de un programa de consejería audiológica por Internet para nuevos usuarios de auxiliares auditivos: un estudio cualitativo. International Journal of Audiology, vol. 45, no. 12, pp. 697-706, 2006.

[11] S. G. Lee, and Y. Lee, The effects of auditory intervention using smartphone application on auditory memory in children with cochlear implants. The 30th Korean Academy of Speech-Language Pathology and Audiology Conference, pp. 307-309, 2016.

[12] J. Yu, H., Chun, C. G. Song, and W. Han, Case study of speech perception enhancement in hearing-impaired adult by auditory training program of mobile device. Audiology and Speech Research, vol. 10, no. 2, pp. 158-168, 2014.

[13] J. Lim, and E. Park, Development and research trends of application as the smart education media for ASD. Journal of the Korean Association for Persons with Autism, vol. 12, no. 1, pp. 93-117, 2012.

[14] N. Tye-Murray, Foundations of aural rehabilitation: Children, adults, and their family members. Plural Publishing, San Diego, 2019.

[15] American Speech-Language-Hearing Association. Technical Report: Cochlear Implants, ASHA Supplement 24, e-pub, 2004. doi:10.1044/policy.TR2004-00041. 
[16] C. C. Dunn, R. S. Tyler, S. Oakley, B. J. Gantz, and W. Noble, Comparison of speech recognition and localization performance in bilateral and unilateral cochlear implant users matched on duration of deafness and age at implantation. Ear and Hearing, vol. 29, no, 3, pp. 352-359, 2008.

[17] N. Tye-Murray, B. Spehar, M. Sommers, and J. Barcroft, Auditory training with frequent communication partners. Journal of Speech, Language, and Hearing Research, vol. 59, no. 4, pp. 871-875, 2016.

[18] F. R. Vogenberg, and J. Santilli, Healthcare trends for 2018. American Health \& Drug Benefits, vol. 11, no. 1, pp. 48-54, 2018.

[19] Y. Lee, Mobile application development for improving auditory memory skills of children with hearing impairment. Audiology and Speech Research, vol. 13, no. 1, pp. 50-61, 2017.

[20] TechNavio. Global Biorefinery Market 2015-2019. Infiniti Research Limited, Toronto, 2014.
[21] T. Lee, ICT Convergence Healthcare Services Status and Future * Strategies. Asia-pacific Journal of Multimedia Services Convergent with Art, Humanities, and Sociology, vol. 7, no. 10, pp. 865-878, 2017.

[22] The Korea Centers for Disease Control and Prevention. Korea National Health and Nutrition Examination Survey 2016. Centers for Disease Control, Osong, 2016.

[23] J. Barcroft, B. Spehar, N. Tye-Murray, and M. Sommers, Task-and talker-specific gains in auditory training. Journal of Speech, Language, and Hearing Research, vol. 59, no. 4, pp. 862-870, 2016.

[24] C. Bexelius, L. Honeth, A. Ekman, M. Eriksson, S. Sandin, D. BaggerSjöbäck, and J. E. Litton. Evaluation of an internet-based hearing testcomparison with established methods for detection of hearing loss. Journal of Medical Internet Research, vol. 10, no. 4, pp. e32, 2008.

[25] App Annie. App Annie mobile app forecast: The path to $\$ 100$ billion. App Annie, New York, 2016.

[26] S. Romanik, Auditory skills program. University of Melbourne, Melbourne, 2008. 